\title{
Silicon nitride for space optical applications
}

Stéphanie Behar-Lafênetre, Philippe Grasset, Nisrine Louh, Laurence Cornillon, Miguel Such-Taboada, et al.

Stéphanie Behar-Lafênetre, Philippe Grasset, Nisrine Louh, Laurence Cornillon, Miguel Such-Taboada, Florent Gant, Vincent Costes, "Silicon nitride for space optical applications," Proc. SPIE 11852, International Conference on Space Optics - ICSO 2020, 118524T (11 June 2021); doi: $10.1117 / 12.2599815$ SPIE. Event: International Conference on Space Optics - ICSO 2021, 2021, Online 


\section{International Conference on Space Optics-ICSO 2020}

Virtual Conference

30 March-2 April 2021

Edited by Bruno Cugny, Zoran Sodnik, and Nikos Karafolas
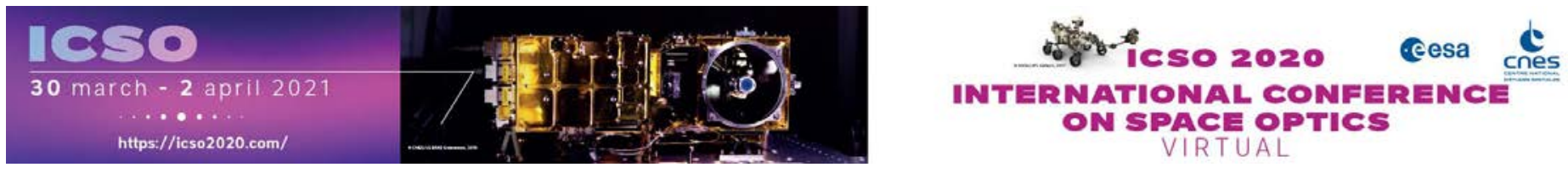

\section{Silicon nitride for space optical applications}

\section{Cesa isopueations ecnes}

International Conference on Space Optics - ICSO 2020, edited by Bruno Cugny, Zoran Sodnik, Nikos Karafolas, Proc. of SPIE Vol. 11852, 118524T · @ 2021 ESA and CNES

CCC code: $0277-786 \mathrm{X} / 21 / \$ 21 \cdot$ doi: $10.1117 / 12.2599815$ 


\title{
Silicon Nitride for optical applications
}

\author{
Stéphanie Behar-Lafenêtre*a, Philippe Grasset ${ }^{\mathrm{a}}$, Nisrine Louh ${ }^{\mathrm{a}}$, Laurence Cornillon ${ }^{\mathrm{a}}$, Miguel Such- \\ Taboada ${ }^{\mathrm{b}}$, Florent Gant ${ }^{\mathrm{c}}$, Vincent Costes $^{\mathrm{c}}$ \\ ${ }^{a}$ Thales Alenia Space, 5 Allée des Gabians, 06150 Cannes, France; ${ }^{b}$ ESA ESTEC, Keplerlaan 1, \\ 2201 AZ Noordwijk, the Netherlands; 'CNES - Centre National d'Etudes Spatiales, 18, avenue \\ Edouard Belin, 31401 Toulouse, France
}

\begin{abstract}
Silicon nitride is a ceramic material that has very interesting stability properties for space telescopes. Indeed, the objective for telescopes is chiefly stability and with its high strength and stiffness and low CTE, Silicon Nitride is well suited for complex space structures.

Thales Alenia Space has demonstrated the ability of $\mathrm{Si}_{3} \mathrm{~N}_{4}$ to address those needs and requirements for complex designs such as tubes, brackets, brazed supports and bars. All these structures have been tested, qualified and flight proven. In addition, deep characterization of the material strength has been performed.

Now that this material has been demonstrated as suitable for telescope structures, several R\&D activities are pursued, from production via additive manufacturing to suitability for optical parts.

This paper shows an overview of past, on-going and foreseen developments for the Silicon Nitride technology.
\end{abstract}

Keywords: Silicon Nitride, space optical instruments, structural parts, additive manufacturing, brazing

\section{INTRODUCTION}

Thales Alenia Space has been using Silicon Nitride for more than a decade for Space structures requiring very high stability and high strength, high stiffness and low mass, typically for optical instruments.

Silicon Nitride has indeed excellent strength properties with respect to other ceramics, as shown in the table below:

- The stiffness-to-mass ratio is optimal and allows lightweighted structures;

- The high strength and high fracture toughness allow safe handling and integration conditions as well as strength during launch;

- The low CTE allows to maintain stability in operating conditions.

Table 1. Properties of Silicon Nitride.

\begin{tabular}{|l|c|c|c|c|c|c|c|c|c|}
\hline Materials & Density & $\begin{array}{c}\text { Young's } \\
\text { Modulus }\end{array}$ & $\begin{array}{c}\text { Poisson's } \\
\text { ratio }\end{array}$ & $\begin{array}{c}\text { Max } \\
\text { Stress } \\
\text { (EN843-5) }\end{array}$ & $\begin{array}{c}\text { Fracture } \\
\text { toughness }\end{array}$ & $\begin{array}{c}\text { CTE @ } \\
\text { ambient }\end{array}$ & $\begin{array}{c}\text { CTE @ } \\
40\end{array}$ & $\begin{array}{c}\text { Thermal } \\
\text { conductivity } \\
\text { @ ambient }\end{array}$ & $\begin{array}{c}\text { Specific } \\
\text { heat } \\
\text { capacity }\end{array}$ \\
\hline & $\rho\left(\mathrm{g} / \mathrm{cm}^{3}\right)$ & $\mathrm{E}(\mathrm{GPa})$ & $v$ & $\mathrm{MPa}$ & MPa.m.5 & $10^{-6} / \mathrm{K}$ & $10^{-6} / \mathrm{K}$ & $\mathrm{K}(\mathrm{W} / \mathrm{mK})$ & $\mathrm{C}(\mathrm{J} / \mathrm{kgK})$ \\
\hline $\mathrm{Si}_{3} \mathrm{~N}_{4}$ & 3.25 & 310 & 0.3 & $>630$ & 7.5 & 1.4 & ca 0.01 & 17 to 50 & 674 \\
\hline
\end{tabular}

Additionally to the mastering of the technology for structural hyper-stable applications (some of them already in flight), Thales Alenia Space in France is also leading since day one a series of technological developments in order to have the state of the art technology for each new application: this paper will describe briefly the developments done on increase of thermal conductivity, brazing and additive manufacturing, paving the way for more complex optical applications.

*stephanie.behar@thalesaleniaspace.com; phone 334929270 00; www.thalesaleniaspace.com 


\section{2. $\mathrm{SI}_{3} \mathrm{~N}_{4}$ HERITAGE}

In the framework of its projects Thales Alenia Space has evaluated the suitability of the technology for complex designs such as tubes, brackets, brazed supports, beams and lightweighted plates. All these structures have been tested, qualified and are now flight proven.

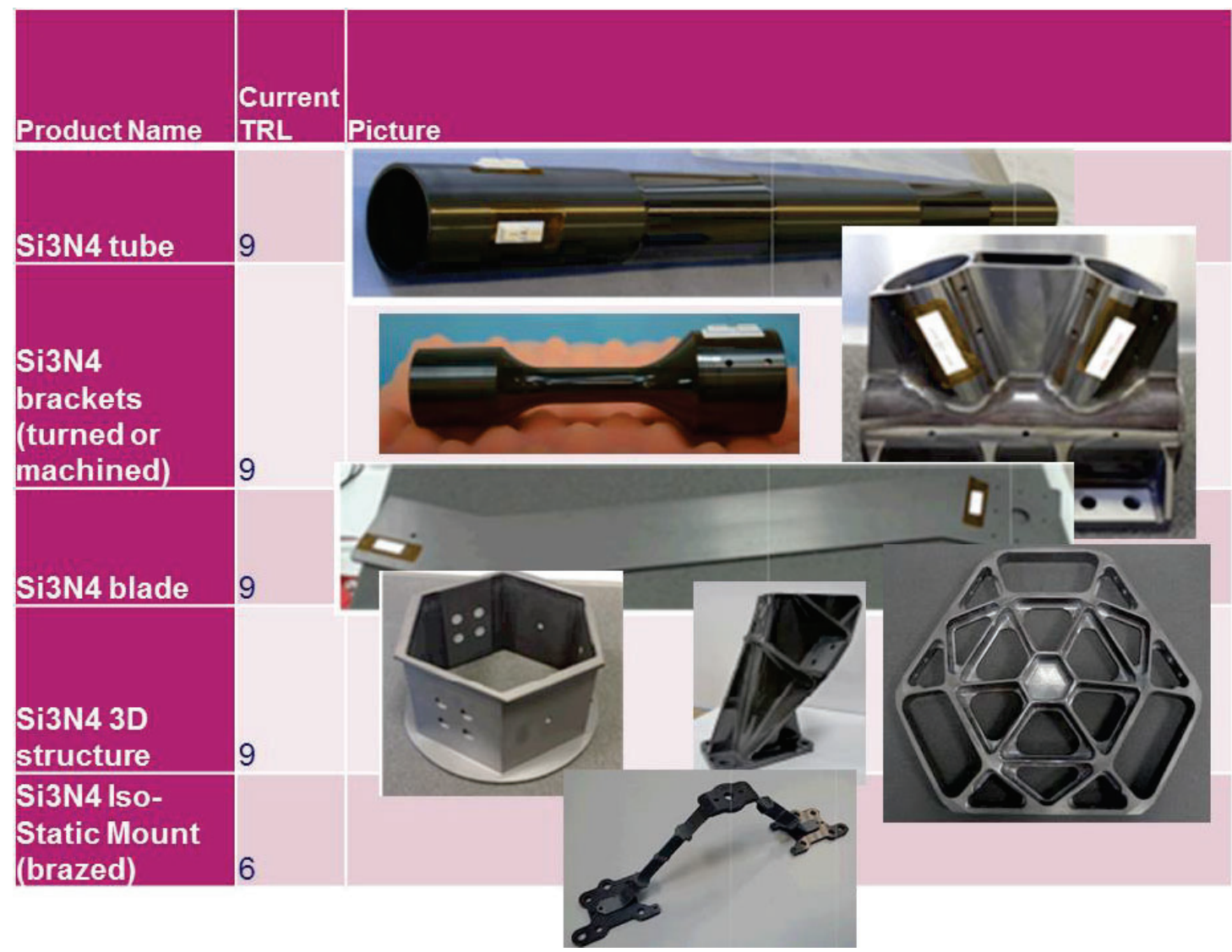

Figure 1. Thales Alenia Space's experience in the use of Silicon Nitride for Space applications.

\section{SI3N4 STRENGTH BEHAVIOR}

In order to improve knowledge and mastering of strength properties, a characterization campaign of the material was implemented in a GSTP funded by CNES and driven by ESA [3].

Ceramic materials have useful mechanical properties (high stiffness to mass ratio, no hygro-elastic effect, low coefficient of thermal expansion) but present a specific behavior with respect to mechanical design and strength, due to the statistical distribution of flaws within the parts and their brittle failure mode. In contrast to metallic materials for which a unique level of stress will drive the failure in any place within the studied parts, ceramic materials exhibit a different level of failure stress depending on the stressed area or volume combined with the statistical distribution of flaws within the part.

Technically, the main particularity of ceramic materials is that they show a brittle failure behavior and have a much higher strength under compressive loads. Therefore, only tensile strength is usually studied. 
Weibull [2] stated that the probabilistic flaw activation can be modeled as a function of the uniform tensile stress in an elementary region. The term "region" means here either volume or area depending on the type of flaws influencing the failure statistics. The material can be characterized in an arbitrary size sample. For the full-scale, the effect introduced by the sample geometry and the stress field can be corrected by means of mathematical equations. the following expression of the failure probability $\mathrm{P}_{\mathrm{f}}$, introducing a so-called "size effect":

$$
\left\{\begin{array}{l}
P f=1-\exp \left(-\frac{R_{e f f}}{R_{o}}\left(\frac{\sigma_{\max }-\sigma_{t h}}{\sigma_{o}}\right)^{m}\right) \\
R_{\text {eff }}=\int_{R / \sigma_{E}>\sigma_{\text {th }}}\left(\frac{\sigma_{E}-\sigma_{\text {th }}}{\sigma_{\max }-\sigma_{t h}}\right)^{m} d R
\end{array}\right.
$$

Where:

- $\quad \mathrm{dR}$ is the elementary region (volume or surface or edge) in the continuous decomposition

- $\sigma_{\mathrm{E}}$, the equivalent failure stress in element $\mathrm{dR}$. The choice of equivalent stress depends on the underlying flaw population (mainly their shape and orientation).

- $\quad \sigma_{\max }$, the maximum equivalent stress over the whole region.

- $\quad R_{\text {eff }}$, called the effective region (usually effective volume $V_{\text {eff }}$ or effective area $A_{\text {eff }}$ ). It corresponds to the region of a specimen submitted to a pure tensile stress $\sigma_{\max }$ with the same failure probability as the real structure.

- $\quad R_{0}$ (meaning either $V_{o}$ or $A_{o}$ ), an arbitrary region for dimensional purpose.

- $\quad \sigma_{0}$, Weibull characteristic strength (corresponding to $P_{f}=0.632$ or $63.2 \%$ when $\sigma_{\text {th }}=0$, scale parameter when $R$ $=\mathrm{R}_{\mathrm{o}}$ ). The value of $\sigma_{\mathrm{o}}$ depends on the chosen arbitrary value for $\mathrm{R}_{\mathrm{o}}$.

- $\quad \sigma_{\text {th }}$, the threshold strength

- $\quad \mathrm{m}$, the Weibull modulus (shape parameter) describing the scatter of the strength data:

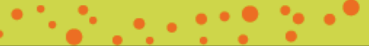
when $\mathrm{m}$ is low, there are a lot of different types and/or sizes of defects in the material so that the level of stress to activate them is also scattered.

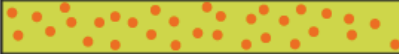

when $\mathrm{m}$ is high, the defects are all very similar, and the level of stress to activate them is less scattered.

This formulation is called the 3-parameter Weibull law. The presence of the threshold $\sigma_{\text {th }}$ corresponds to the fact that below that stress level, the failure probability is zero. This can be related to a maximum size of flaws in the material.

$\mathrm{R}_{\mathrm{eff}}$ depends on the stress distribution and geometry of the structure, but also on the Weibull modulus $\mathrm{m}$ that is materialdependent.

This has been the theoretical basis for the definition of a thorough test campaign allowing to accurately identify the Weibull parameters and confirm that the material is well mastered, both in the production process and in its implementation.

Thales Alenia Space has a test laboratory dedicated to ceramic materials, with in-house developed test rigs for four-point bend, ring-on-ring, O-ring and C-ring tests, according to standard testing requirements, or customized tensile tests, as shown in Fig. $5.100 \mathrm{kN}$ and $250 \mathrm{kN}$ tension/compression machines are used to operate those tests:
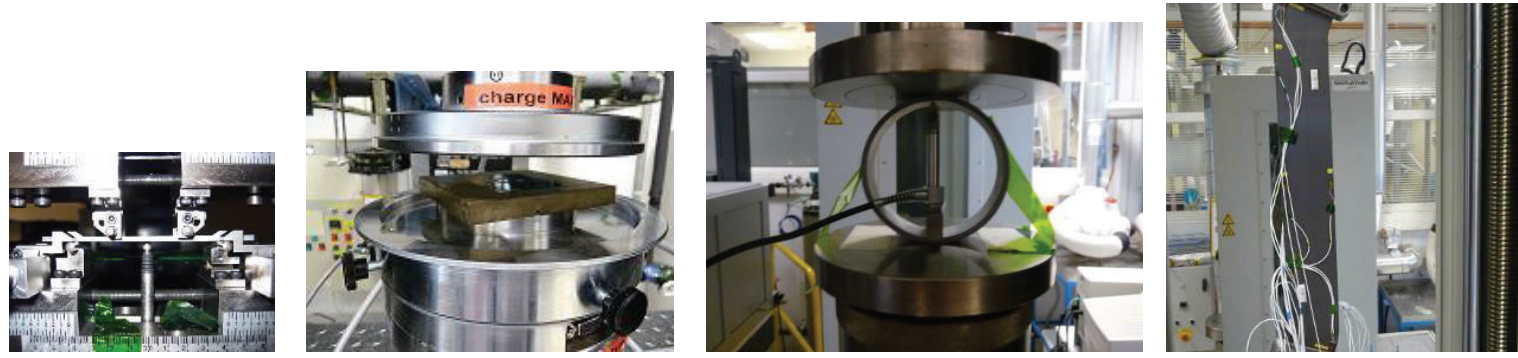

Figure 2. LEFM - Thales Alenia Space's mechanical test lab can perform a wide variety of tests: 4-point bending, ring-onring, $\mathrm{O}$ - and $\mathrm{C}$-ring, tensile 
The following table describes the complete set of test pieces. The necessary ratio of 10 from one sample to the other is respected, as recommended in literature in order to be able to discriminate size effects. Considering the value of $\mathrm{m}$ (15), the expected scatter of the material is sufficiently low so that 30 test pieces in each sample are enough to determine accurately the Weibull parameters.

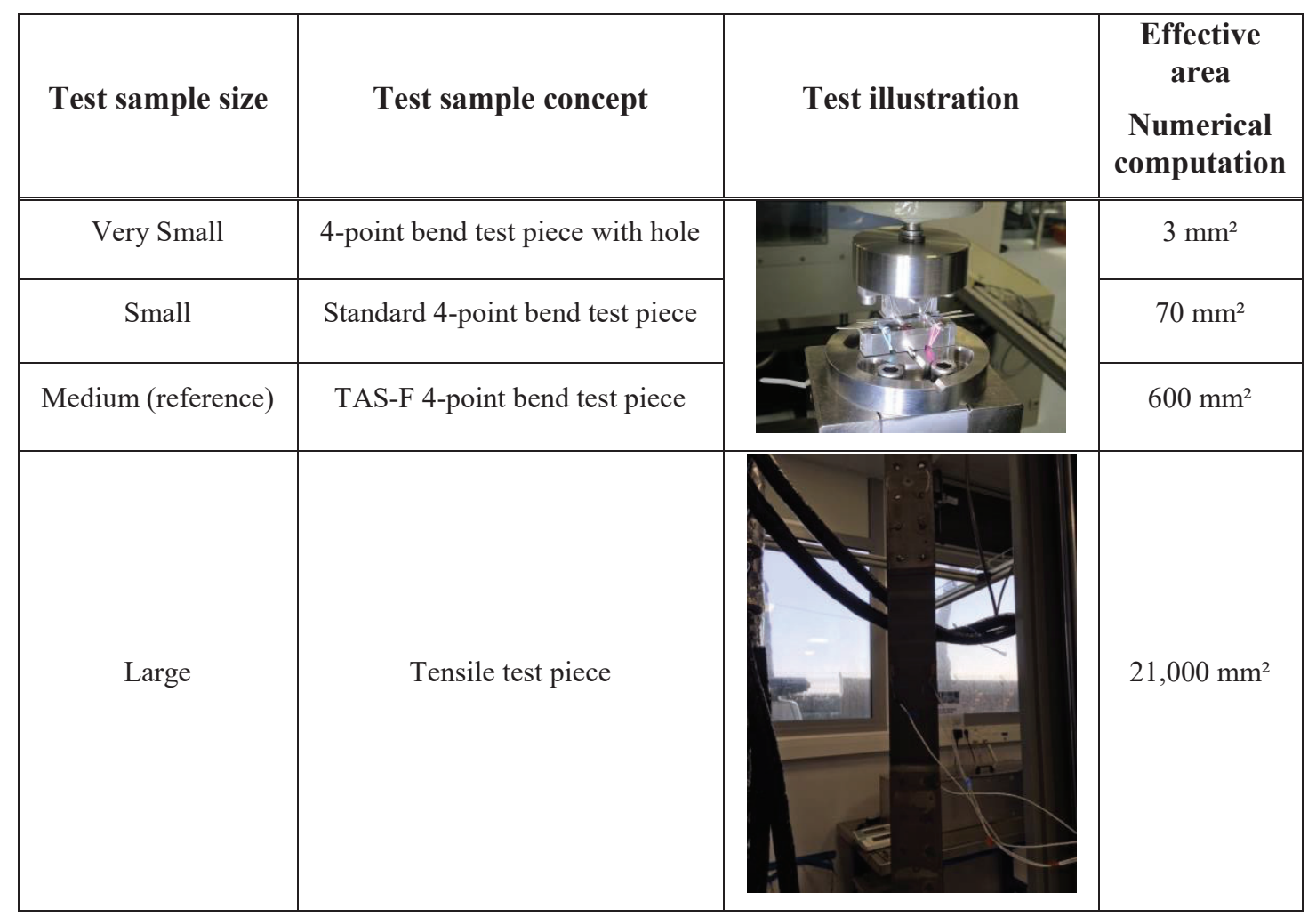

This test campaign has allowed Thales Alenia Space to answer several questions raised at the start of the study:

1. The first question was whether Silicon Nitride was indeed subject to size effects as predicted by the Weibull theory for brittle materials.

The answer is yes: by testing four different samples with different effective regions, it has been evidenced that there is an effect of size, as illustrated below with several plots and by the evolution of the average failure stress:
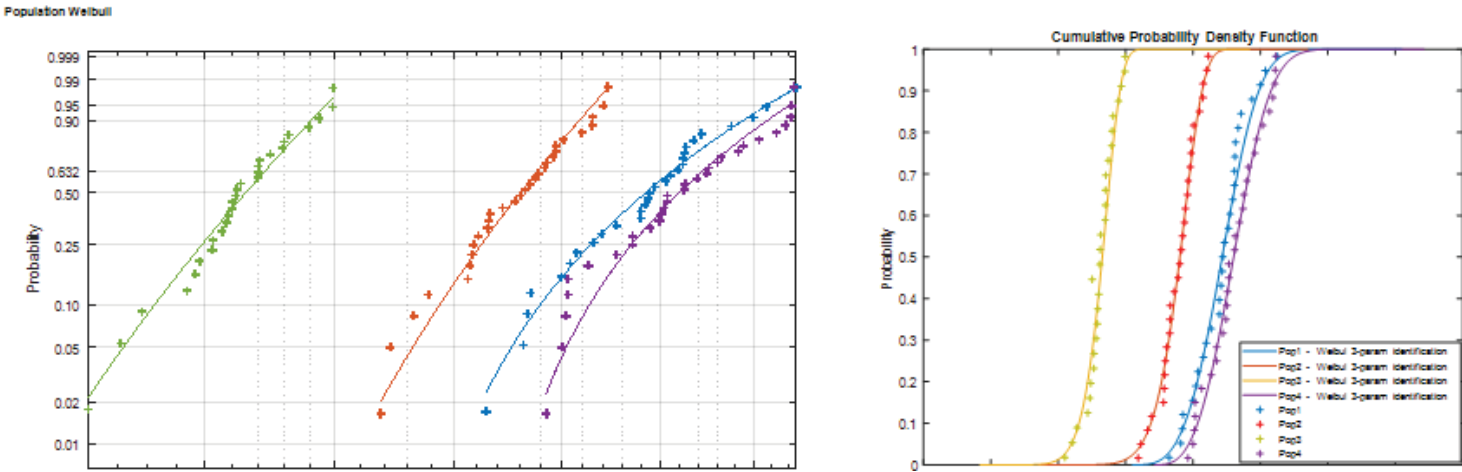

Figure 3. Illustration of a size effect on Silicon Nitride. Left: on the Weibull plot ; right: on the cumulated probability density functions 
It also has been demonstrated that the driving region is surface as most failures occurred at the surface and the pooling has been possible with a surface correction.

2. Then the question was whether Silicon Nitride exhibited a threshold behaviour.

The answer here again is yes: both 2-parameter and 3-parameter identifications have been tried and only a 3-parameter law allows to fit the data well enough.
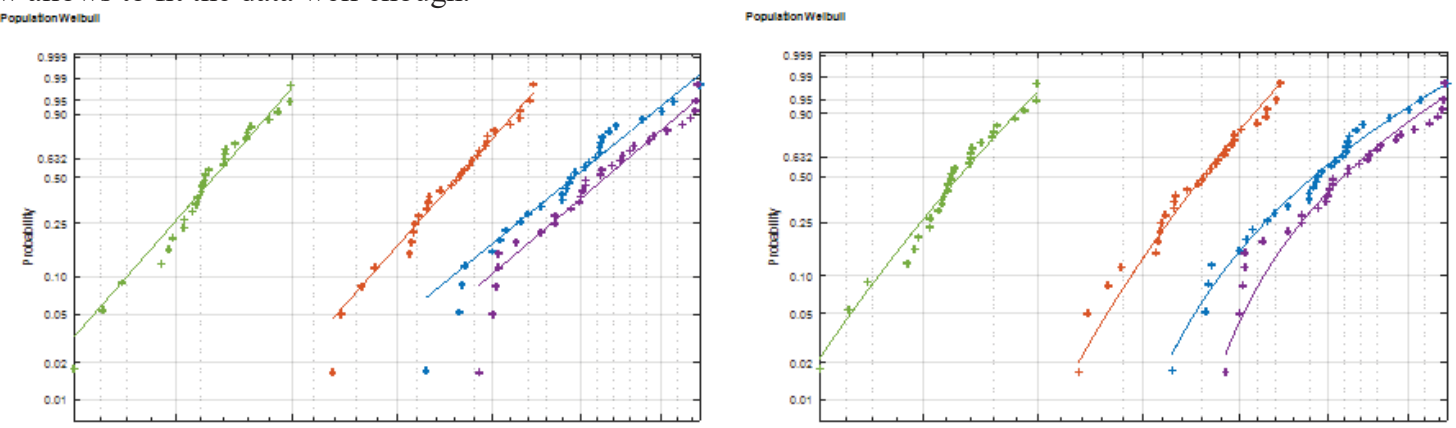

Figure 4. Comparison of 2-parameter (left) and 3-parameter (right) identifications: the 3-parameter (with threshold) gives better results

\section{Can this threshold be predicted based on non-destructive testing ?}

The answer here is: "not with X-ray tomography", as it has been found impossible to correlate the flaws found by fractography as the origins of failure and the flaws identified by X-ray tomography.

This can be explained because failure occurred in the great majority of cases on the surface of the specimen, where X-ray tomography can only identify volume flaws.

A potential for improvement is therefore to investigate non-destructive testing techniques allowing to identify surface flaws

\section{Practical impacts for sizing}

In practice it is proposed to use the identified parameters for any effective area between those of Pop1 and Pop3, for the surface finish tested in the project. This should cover the most common situations encountered in space applications.

Such parameters however have to be knocked down in order to perform sizing with the necessary level of reliability, based on the recommendations of the handbook [1].

Basically this test campaign has allowed to demonstrate the very good reproducibility of the $\mathrm{Si}_{3} \mathrm{~N}_{4}$ manufacturing process, and the reliability of the sizing methodology when associated to sound characterization tests. 


\section{4. $\mathrm{SI}_{3} \mathrm{~N}_{4}$ WITH INCREASED THERMAL CONDUCTIVITY}

Now that it is ensured that the baseline material is reliable, additional improvements can be brought, in particular increase of the thermal conductivity, which can be useful for optical applications.

The interest of working on the properties of Silicon Nitride in order to obtain a material with higher thermal conductivity without decreasing mechanical properties and without increasing CTE has been highlighted in 2008 and studied in the frame of R\&T contracts. The first study consisted in defining specific Silicon Nitride formulations in order to increase the thermal conductivity. Indeed, as silicon nitride is a multiphasic ceramic material with a large content of sintering additives, it is possible to enhance its properties by adapting the type of additives. After an exhaustive bibliographic study and several tests in order to select the most adapted solutions, it has been assessed that the work on sintering additives was necessary and sufficient before any other modification (replacement of standard powders or addition of high-conductivity particles). The first part of the study was to manufacture and test small samples. Very good results have been obtained in term of thermal properties and mechanical properties. Nevertheless, the sintering cycle parameters applied for the manufacturing of these small samples were quite specific.

Next step of the study has consisted in manufacturing some bigger parts with this new selected formulation, in order to demonstrate the manufacturability of scale 1 parts. This industrialization phase requires that it is possible to sinter the new material with other parts from compatible grades in the same furnace runs, and thus with the same sintering cycle parameters. It has thus been decided to make a compromise on the properties of the new material, in order to insure the industrialization of the new grade and to secure its reproducibility and future maturity.

Some plates have been manufactured with different manufacturing batches and some strength tests have been performed. A good reproducibility between the different batches has been obtained. Four tubes have been also manufactured with this grade. The length of the tubes is $500 \mathrm{~mm}$; apart this length, other parameters are representative of scale 1 tubes. One of this tube has been sliced and the slices have been tested in O-ring tests. The obtained average strength is slightly lower than the one of the reference grade, but with a remarkable good reproducibility, really improved compared to reference grade.

The thermal conductivity is lower than the one obtained on first small samples, (around $50 \mathrm{~W} / \mathrm{mK}$ ) but it allows the manufacturing of large parts with a good mechanical behavior.

After this intermediate step, the manufacturing processes parameters have been frozen, and four scale 1 tubes have been manufactured and tested. Thermal conductivity, coefficient and thermal expansion have been confirmed on samples machined directly from these scale 1 parts. Mechanical tests have been also performed and proved again a good reproducibility and homogeneity of the parts (cf. Figure 5 which shows the strength homogeneity along the tube length). The tensile strength is higher than the industrial grade (cf. Figure 6 : tensile test on a scale 1 tube)); it seems that this grade has also a higher fracture toughness.

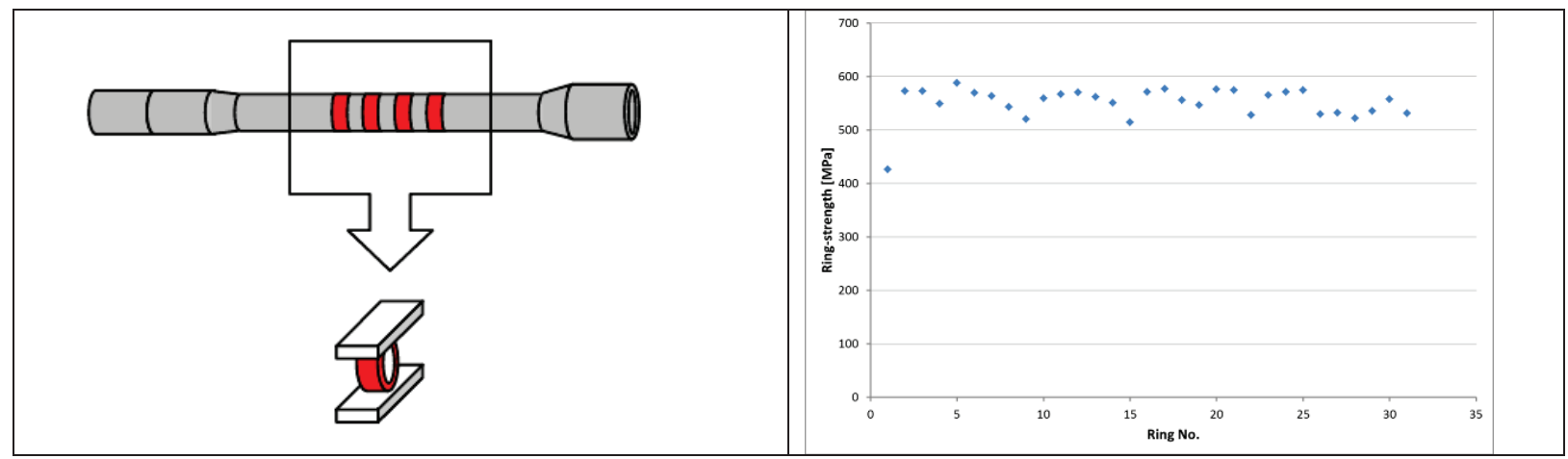

Figure 5. Machining of the O-ring samples from a scale 1 tube (left); strength results obtained along the tube (right) 
As a conclusion, this study has allowed to identify a grade with an improved thermal conductivity and which can be easily manufactured. Results obtained on scale 1 tube are very encouraging : in particular a very good reproducibility is obtained along the length of the tubes, and also between the different tested batches.

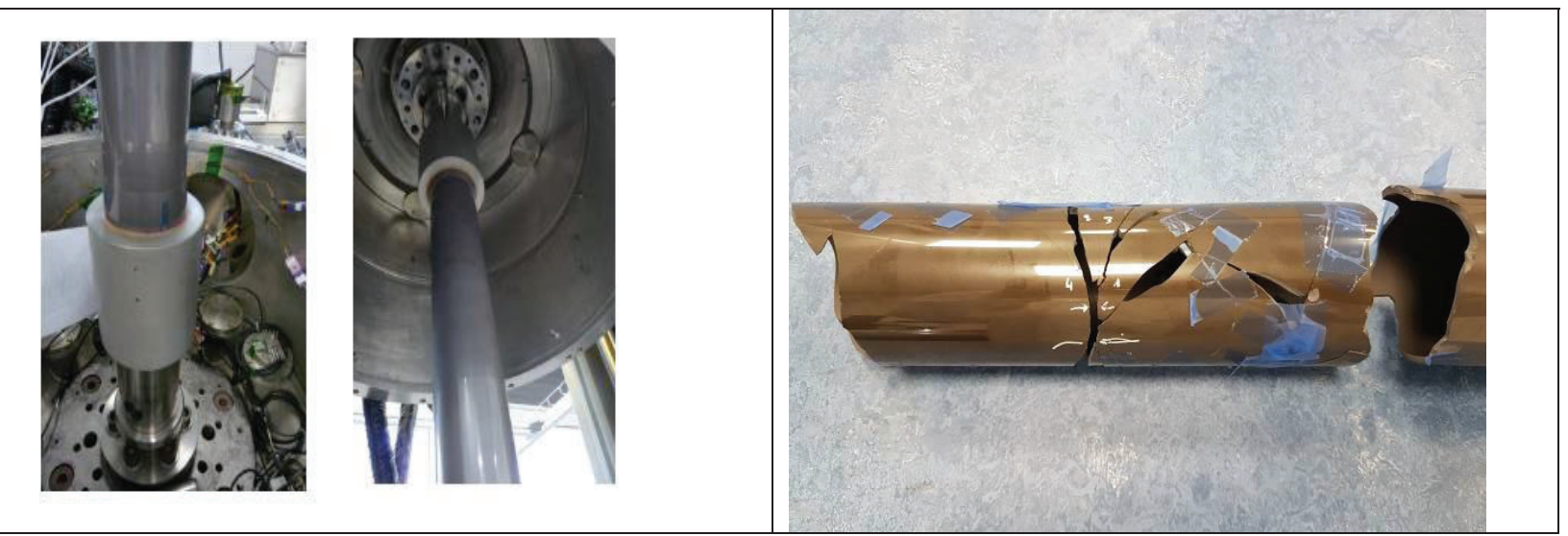

Figure 6. tensile testing of scale 1 tube : test facility (left); tube parts after failure (fractography analysis)(right)

This activity has allowed to design a $\mathrm{Si}_{3} \mathrm{~N}_{4}$ grade that has an improved thermal conductivity. This opens perspectives for specific applications that require a higher thermal performance.

\section{BRAZING OF SI3N4}

In order to benefit from the good properties of silicon nitride on extended size or for more complex shapes without jeopardizing stability or integration time, brazing developments activities have been launched under CNES funding, in collaboration with FCT I for the manufacturing of ceramic parts, and with PMB for the brazing junctions (PMB is a specialist of metallic - ceramic brazed junctions) [5]. Brazing technology allows to assemble structurally some parts, and thus to avoid adhesive bonds.

Two main applications have been selected for the first experiments : the brazing of tubular parts like tubes, and the brazing of plane sections for the manufacturing of supports. The chosen philosophy was to select the same brazing alloy for the two applications and also the same brazing curing cycle.
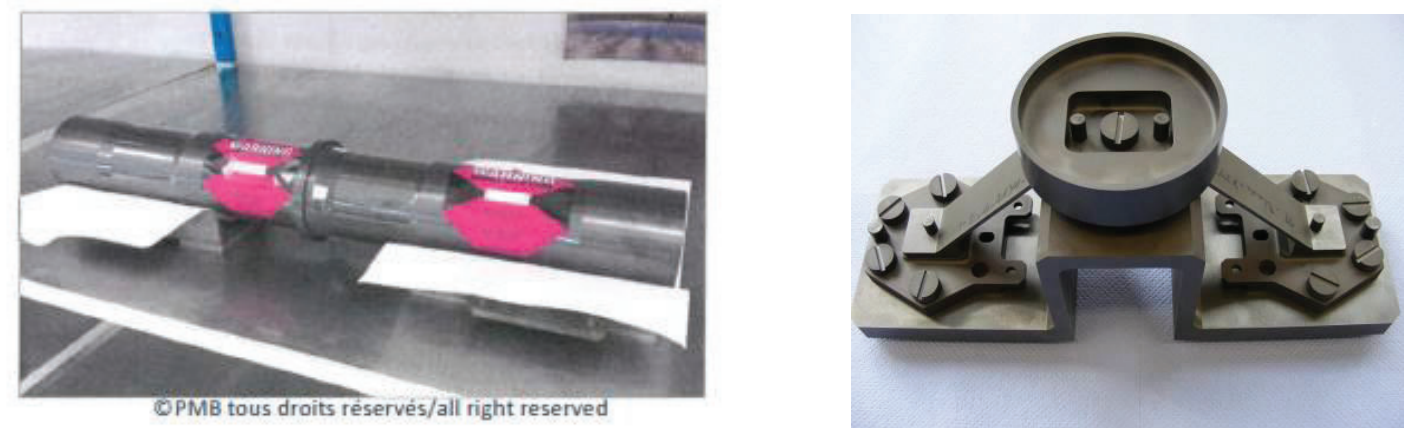

Figure 7 Si3N4 brazed parts (left: Brazed assembly of two short tubes in silicon nitride ; right : Brazed simplified prototype of silicon nitride supports)

At the beginning of the study, an extensive bibliographic study and tests on several solutions have shown that active metal brazing was the most interesting solution, in term of mechanical strength of the brazed joint. Active Brazing 
Alloys eliminate the need for traditional ceramic metallization prior to brazing as the active components promotes wetting on the ceramic surface.

Then tests have been performed on samples brazed with different active metal brazing alloys, in order to select the brazing composition and also the brazing parameters: initial thickness of the braze alloy, pressure to apply, brazing cycle (and in particular temperature). Micro-sections observations after brazing, showing the general aspect of the joint, the thickness of the joint after brazing, the microstructure, the sensitivity to moisture and oxidation, have allowed to select the most promising solutions.

Then mechanical tests have been performed. At this step of the study, the chosen test was 4-point bending, on samples brazed on their middle (Cf. Figure 8). These mechanical tests and complementary analyses like optical microscopy and Scanning Electronic Microscopy (SEM) have allowed to validate the most adapted parameters. The strength of the joint after thermal cycling and thermal ageing has been also studied. No decrease has been noticed after this kind of treatment. The aspect of the joint is the same before and after such treatment.

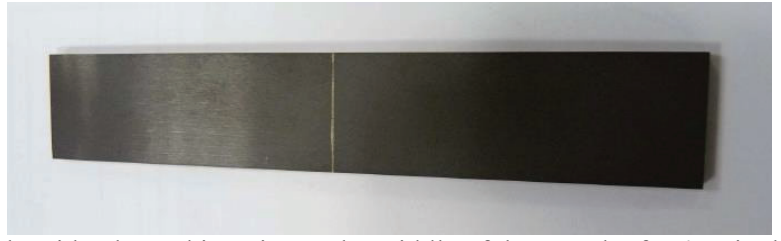

Figure 8. Silicon nitride sample with a brazed junction at the middle of the sample, for 4-point bending tests

One of the most important requirement of silicon nitride brazed assemblies is the high strength of the assembly. It was thus very important to determine and predict the strength behavior of the brazed joint.

Work on elementary samples was performed in order to ease the manufacturing of the samples and thus to increase the number of tests results.

The first chosen test, during the first phase, was 4-point bending, due to the simplicity of the ceramic part manufacturing and test.

Then in order to be more representative of our final application it was decided to work on a double shearing sample geometry, (dimensions of the brazed areas, general geometry of the surfaces to be brazed with respect to the geometry of the sample, and the way to apply the pressure). This geometry is also more reliable from the point of view of brazing (to respect general tolerances on brazed samples geometry).

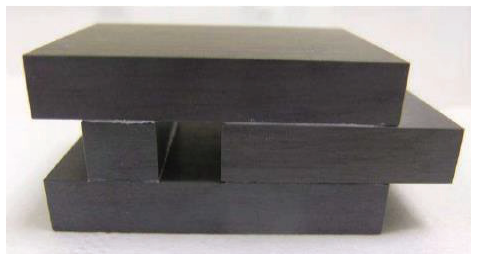

Figure 9 Silicon nitride sample with brazed junctions for double shearing tests

Thanks to this test, the shearing strength of the brazed joint is accessible with a simple test facility, and on a sample geometry representative of the application real geometry. Reproducible results have been obtained. This kind of samples is now used as witness samples, brazed at the same time as real complex parts

After this first phase of the project, some tests on real geometry have been launched, for two applications : the brazing of tubes, and the brazing of plane sections for the manufacturing of supports. The tests results were satisfying complying with margins on the required strength to support qualification loads and in agreement with Finite Element Calculations and results obtained on samples. 


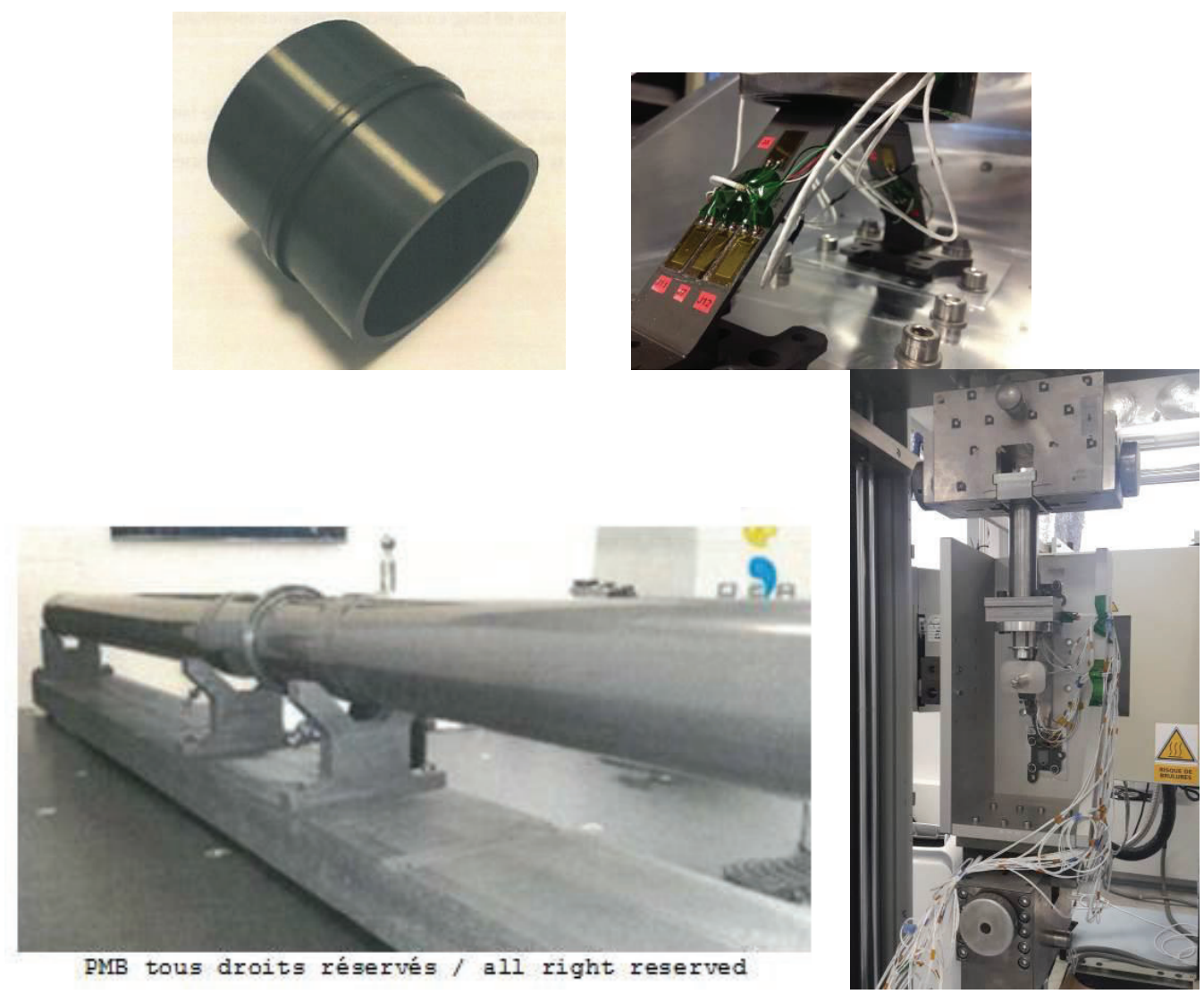

Figure 10 Upper left: Ceramic rings after brazing; Upper right: Simplified prototype of brazed support during the mechanical testing (parts equipped with strain gauges) ; Lower left: Scale 1 brazed tubes ; Lower right: Mechanical tests on representative prototype of brazed ceramic support

This activity has allowed to define a reliable process for assembly of complex parts made by the classical manufacturing process.

\section{SI3N4 BY ADDITIVE MANUFACTURING}

Considering the very good mechanical behavior of Silicon Nitride and the latest developments in the field of additive manufacturing, investigations on the potential of additive manufacturing have been launched.

Between 2014 and 2018 Thales Alenia Space, with CNES co-funding, investigated the several existing technologies for additive manufacturing of ceramic materials. This led to the choice of the SLM (Selective Laser Melting) for the production of the greenbody, followed by classical sintering, a process already well mastered by 3DCeram, then a small French company, for alumina.

The first developments with Silicon Nitride gave very encouraging results: after producing 4-point bend test pieces (identical to the "small" sample used for the classical material, see section 3): the same Weibull behavior as classical ceramics was demonstrated, with an average strength just a bit lower than the reference material: 

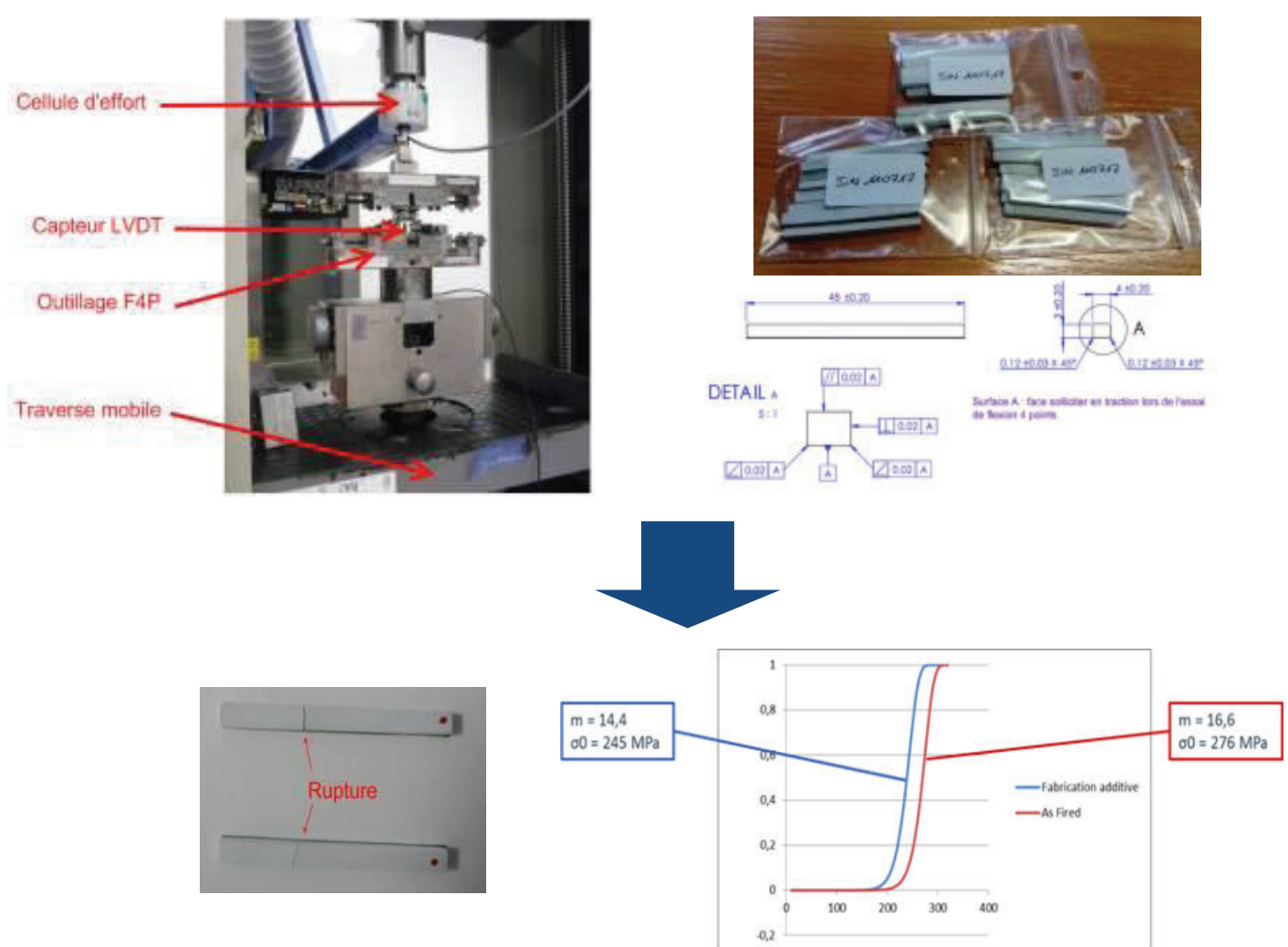

Figure 11. First characterizations of $\mathrm{Si}_{3} \mathrm{~N}_{4}$ produced by additive manufacturing gave strength values very close to the reference

While developments on the material itself were led, a first prototype, based on classical mirrors designs, was produced. Features such as turned out edges, small second-level flanges and small corner radii difficult to produce with classical machining have been tried, with successful results:
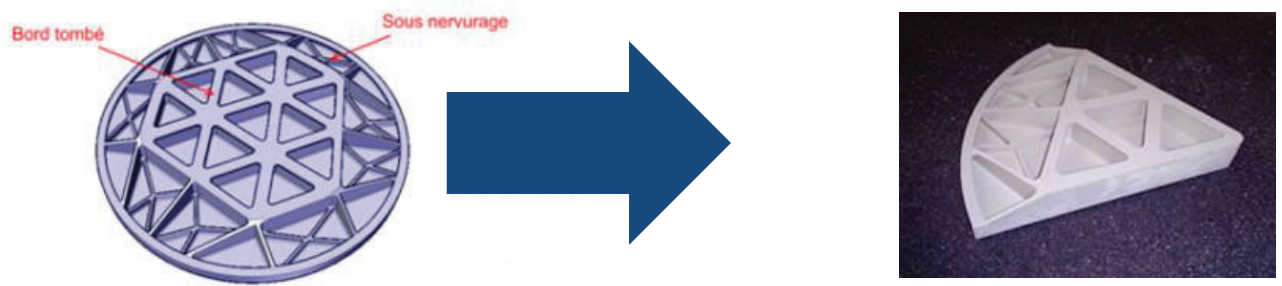

Figure 12. First demonstration of $\mathrm{Si}_{3} \mathrm{~N}_{4}$ mirror structure made by additive manufacturing, showing the possibility to make complex structural features such as turned out edges, small second-level flanges and small corner radii difficult to produce with classical machining

Based on such encouraging results it was decided to follow-up in order to increase knowledge on formulation quality, reproducibility, availability, etc... and processing (improvement of layers' homogeneity, cleaning, debinding, sintering). The outcome was here again very successful: the layers adhesion quality was very much improved, and strength was even better mastered: 


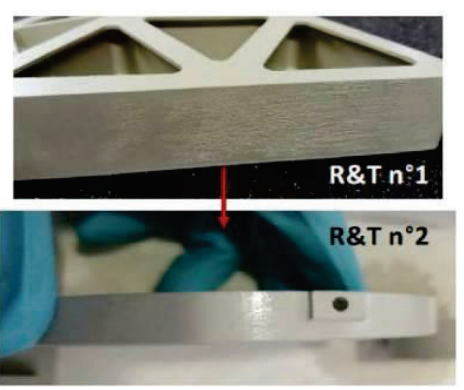

Figure 13. 2019: improvement of process - layers' quality
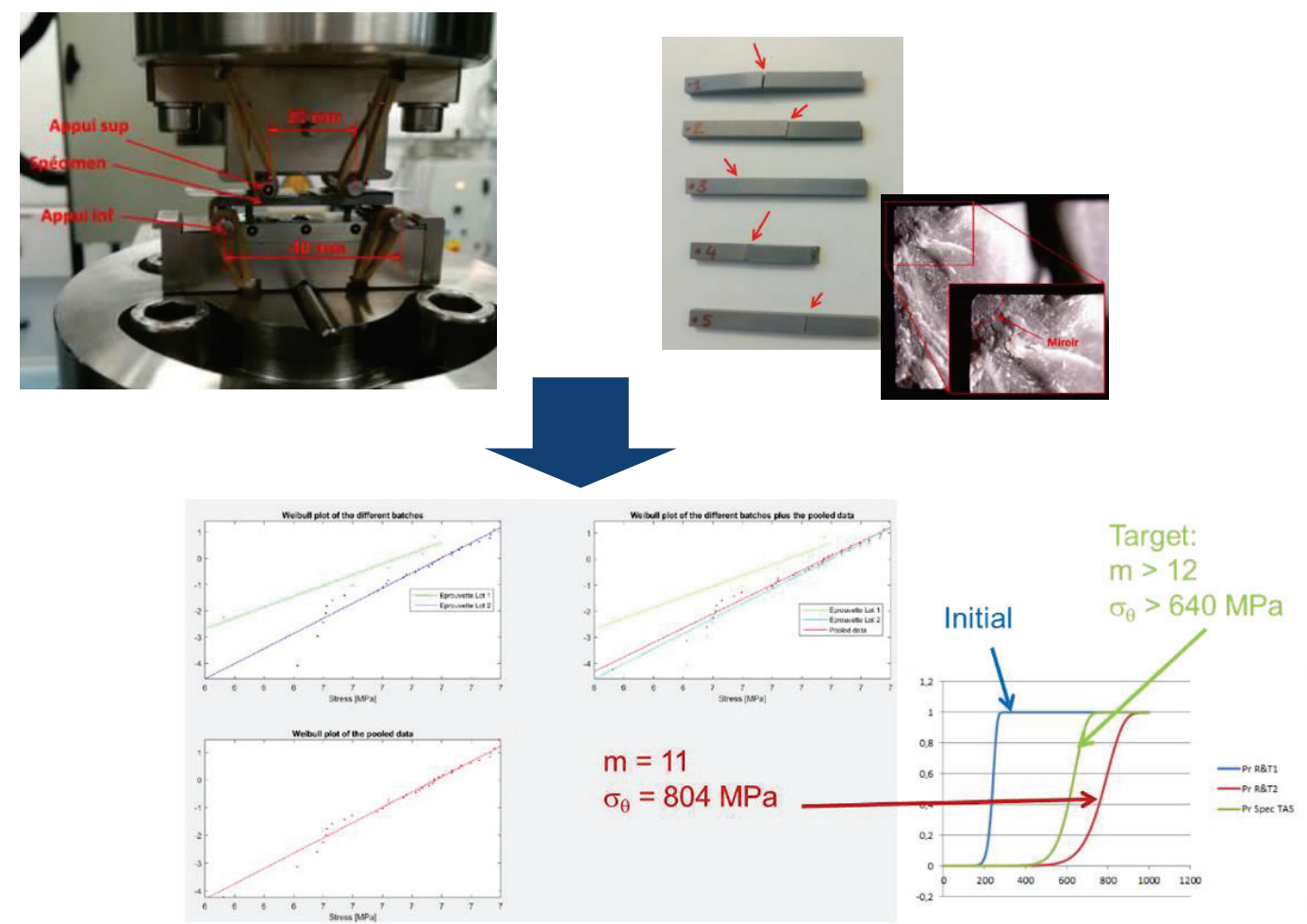

Figure 14. 2019: improvement of strength, both in terms of average and scatter

A parallel study [6] was also performed under CNES funding in order to assess whether additive manufacturing would be interesting for mirrors, whatever the material. The knowledge that additive manufacturing allows much more shape versatility led to the application of topology optimization under optical criteria (typically Wave-Front Error under gravity), with surprising, organic-like shapes as shown in the following illustration. The additive manufacturing process for alumina at $3 \mathrm{DC}$ Ceram being the same as for $\mathrm{Si}_{3} \mathrm{~N}_{4}$ but more mature for larger sizes, an attempt at producing such shape was decided, and worked out successfully as shown in the picture. 

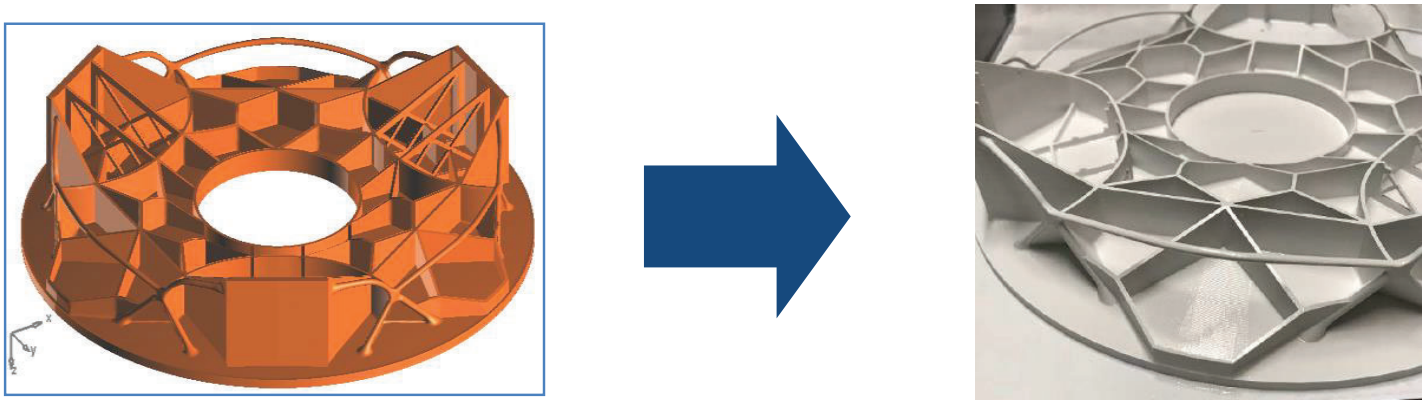

Figure 15. First demonstration of alumina mirror structure made by additive manufacturing based on an optimized design

It is therefore very likely that in the future additive manufacturing allows versatile and innovative designs for mirrors, even with such special materials as ceramics.

\section{NEXT STEPS AND PERSPECTIVES}

As a summary, several developments are ongoing and promising on Silicon Nitride:

- Thales Alenia Space has up to now a more than 10 years fruitful cooperation with FCT Ingenieurkeramik, which has led to flight-proven, very stable and reliable structural items, with more and more complex shapes, starting out with tubes and now going to complex 3D shapes with the classical manufacturing process.

- Developments have allowed to improve the classical grade to increase its thermal conductivity. On-going activities are intended to further mature this technology.

- Iso-static mounts made by additive manufacturing have been qualified under harsh mechanical environment and full performance has been demonstrated.

Now additive manufacturing allows us to dream of even more complex products, such as mirrors, why not: Thales Seso has tested on internal funding polishing of coupons with the "high conductivity" grade and reached a roughness down to $\mathrm{nm}$ RMS which could be fully acceptable for applications in the NIR/SWIR wavelengths. If necessary, a $\mathrm{SiO}_{2}$ coating could be developed since its thermal characteristics are very close to $\mathrm{Si}_{3} \mathrm{~N}_{4}$ 's.

\section{ACKNOWLEDGEMENTS}

The GSTP activity on material characterisation was funded by CNES and DLR via a three-partners contract between ESA, Thales Alenia Space ( ${ }^{\circ} 4000115657 / 15 / \mathrm{NL} / \mathrm{BJ} / \mathrm{gp}$ ).

All test pieces have been manufactured by FCT Ingenieurkeramik, and X-rayed by Fraunhofer HTL Bayreuth.

The authors wish to thank their students Thomas, Omar and Rachid for their participation to the post-processing of data.

CNES co-funded R\&T activities on:

- increased thermal conductivity, activities led by Thales Alenia Space in France with FCT Ingenieurkeramik

- $\quad$ iso-static mount brazing, activities led by Thales Alenia Space in France with FCT Ingenieurkeramik and PMB

- additive manufacturing, activities led by Thales Alenia Space in France with 3DCeram 


\section{REFERENCES}

[1] Mechanical Design and Verification of Ceramic Structures Handbook.

[2] Weibull W., A statistical distribution function of wide applicability, J. Appl. Mech. 18 (3), 293-297 (Sept. 1951)

[3] Stéphanie Behar-Lafenêtre, Nisrine Louh, Philippe Grasset, Laurence Cornillon, Miguel Such-Taboada, "Silicon nitride for structural parts of space applications," Proc. SPIE 11101, Material Technologies and Applications to Optics, Structures, Components, and Sub-Systems IV, 1110103 (30 August 2019); https://doi.org/10.1117/12.2529078

[4] L. Cornillon, C. Devilliers, S. Behar-Lafenêtre, S. Ait Zaid, K. Berroth, A.C. Bravo, Silicon nitride ceramic developments in Thales Alenia Space: qualification achievement and further developments for future applications

[5] L. Cornillon, P. Grasset, C. Devilliers, S. Behar-Lafenêtre; N. Louh, A. C Bravo, T. Campanella, F. Gant, Development of strong resistance brazing joints for silicon nitride ceramic parts for space applications, Proc. ECSSMET 2016

[6] Nisrine Louh, "Optical mirrors design using topology optimization for additive manufacturing (Conference Presentation)," Proc. SPIE 11101, Material Technologies and Applications to Optics, Structures, Components, and Sub-Systems IV, 111010G (10 September 2019); https://doi.org/10.1117/12.2529515 